\title{
Security Preparedness and Organizational Operations in Laikipia County, Kenya
}

\author{
Murithi Lawrence Muthee ${ }^{1, *}$, Philip Wambua Peter² \\ ${ }^{1}$ School of Diplomacy and Peace Studies, Kenyatta University, Nairobi, Kenya \\ ${ }^{2}$ School of Business, Kenyatta University, Nairobi, Kenya
}

Email address:

lawimuri@gmail.com (M. L. Muthee)

${ }^{*}$ Corresponding author

\section{To cite this article:}

Murithi Lawrence Muthee, Philip Wambua Peter. Security Preparedness and Organizational Operations in Laikipia County, Kenya. Social Sciences. Vol. 9, No. 5, 2020, pp. 195-211. doi: 10.11648/j.ss.20200905.19

Received: September 14, 2020; Accepted: October 6, 2020; Published: October 22, 2020

\begin{abstract}
The aim of the study was to establish how availability of closed circuit television, security services, firefighting equipment and medical facilities contributed to organizational operations. Descriptive research was adopted in the study to identify how organizational operations are affected by security preparedness. The study targeted a population of one thousand one hundred respondents comprising of business owners, heads of institutions, security operatives and clients out of which a sample size of one hundred and ten respondents was selected. The study collected both primary and secondary data using semistructured questionnaire and reviewed empirical and theoretical literatures respectively. The collected data was analyzed using Statistical Package for Social Sciences (SPSS) and presented in pie charts, bar charts and graphs. Pilot testing of the instruments was conducted to ascertain their reliability. The study findings indicated that there is a positive and important relationship between CCTV and organizational operations. Likewise, there was a positively significant correlation between security service personnel and organizational operations. The effect of firefighting equipment on organizational operations was moderate according to the study findings. Additionally, the study found out that the influence of medical facilities on organizational operations was moderate. The study recommends an increase of CCTV coverage within Nanyuki, modernization of firefighting equipment, standardized operating procedures for security service providers and an evaluation of preparedness of medical facilities within Nanyuki town on the ability for mass casualty response.
\end{abstract}

Keywords: Security, Preparedness, Organizational, Operations

\section{Introduction}

\subsection{Background to the Study}

Gimode, Edwin A notes that there can be no pursuit of meaningful sustainable development in a situation marked by uncontrolled crime, because it breeds and accomplishes insecurity [11]. Security preparedness for organizations continues to be a key determinant of organizations effectiveness in delivering their core mandates and functions. The Department of Homeland Security in the U. S notes that security preparedness is a continuous cycle of planning, organizing, training, equipping, exercising, evaluating and taking corrective action in an effort to ensure effective coordination during incident response [9]. On the other hand, organizational operations majorly deal with how organizations that may include business enterprises or institutions gets their things done.

Cannon, B. observed that $9 / 11$ attacks did have a significant impact. They highlighted the country to the vulnerability of their own way of life [5]. The attack brought to fore the vulnerability associated with weakly guarded 'soft' targets. Leidel, S. defines "soft" target as a person, who due to their actions and/ or a lack of a protective measure, is at the mercy of existing risks and thus represents an easy target. On the other hand, a "hard" target is a person who due to their actions and/or appropriate protective measure, is able to minimize 
existing risks and thus most likely represents an unattractive target [19]. Kalvach $Z$ et al defines 'soft target' as places with high concentration of people and low degree of security against assault creating an attractive target especially for terrorist [14]. Examples of soft targets include schools, religious sites and places of worship, shopping centers, concert halls, entertainment venues, sporting arenas and stadiums. LaTourrette $\mathrm{T}$, warned that amenities in which a large number of people are present and in high concentration such as office buildings, auditoriums, and shopping centers are attractive targets for terrorists [18]. Entrepreneurs in such facilities are becoming increasingly concerned about their exposure to terrorist attacks and how they may reduce their risk.

Wafula, P, has noted that since the launch of Operation Linda Nchi in 2011, Kenya had witnessed 100 successful attacks by Al-shabaab terror group by 2014 [33]. Two serious attacks conducted by the group include the Westgate mall attack and the Garisa University attack. Following a successful attack at Garisa University for instance, Barnett, $\mathrm{H}$ observed that the terror group posted on its website observing that "no amount of precaution or safety measure will be able to guarantee your safety, thwart another attack or prevent another bloodbath [3]. Such a statement is a serious call for security preparedness at all levels.

CCTV, firefighting equipment, security service personnel and well equipped and staffed medical facilities have the potential of mitigating security threats to a large extent. The four are key in enhancing security preparedness and ensuring that opportunistic chances that expose an organization to insecurity are neutralized and when it happens, an organization remains steadfast and resilient and is able to absorb the emanating shock.

According to Kenya Information guide, Laikipia County is one of the 47 counties of Kenya lying on the Equator in the former Rift Valley province. It is a cosmopolitan county covering approximately $8,696 \mathrm{~km}^{2}$ [17]. Laikipia County has two major towns namely Nanyuki and Nyahururu. Small arms are easily available in Laikipia County. Langat, A noted that one resident of Baringo County when asked who sells them the guns replied that the arms are usually trafficked into the town of Rumuruti in bordering Laikipia County by traders who come to buy cattle at the market [18]. Nanyuki town is close to Isiolo County which is believed to be a major source of radicalized youth who join Al-Shabaab. Maithya, I. observed that an estimated 200 under age kids reported missing since 2014 were assumed to have crossed over to Somalia [21].

\subsection{Statement of the Problem}

Musau, N. observes that the parliamentary report rejected by the national assembly on Westgate attack noted that despite numerous terror attacks in the country in the past, the security forces level of preparedness to deal with the situation had largely remained low [26]. While many other functions were devolved to county government following the passing of the 2010 constitution, security still remains under the ambit of the national government. After Garisa University terror attack, Methu, $\mathrm{S}$ noted that the U. S government warned of possible attacks "throughout Kenya in the near term" [25]. Terrorists have shown the intent and ability to strike at the most vulnerable points with their successful planning and carrying out attacks on Westgate and Garissa University, and the inability of our forces to coordinate a serious rescue mission.

A lot of research has been done on the impact of terror attacks on the economy, the impact on social, political and environmental spheres. Previous researches have not addressed the impact of security preparedness on organizational operations and how counties are prepared to face the phenomenon. This study was conducted to investigate security preparedness and organizational operations in Laikipia County.

\subsection{Objectives of the Study}

The aim of the study was to establish security preparedness and organizational operations in Laikipia County in relation to availability of CCTV, security service personnel, firefighting equipment and medical facilities. The following were the specific objectives.

(i) To find out the effect of CCTV on organizational operations in Laikipia County.

(ii) To establish how security service personnel influence organizational operations in Laikipia County.

(iii) To determine the effect of firefighting equipment on organizational operations in Laikipia County.

(iv) To investigate how medical facilities influence organizational operations in Laikipia County

\section{Literature Review}

\subsection{Theoretical Review}

\subsubsection{Securitization Theory}

Securitization theory emerged in 1990s and from then on, it has become the principal critical approach to the study of security. Securitization, as a concept, originated from the writings of Ole Wæver. Security: A New Framework for Analysis (Buzan, Waever and Wilde, 1998) which is identified as the key foundational text in securitization studies. According to Buzzan et al securitization is an inter-subjective establishment of an existential threat, which demands urgent and immediate attention, as well as the use of extraordinary measures to counter the threat [4]. Whether or not something is considered a security issue depends on the subjective understanding of security on the part of these actors and the context in which they decide to represent an issue as such. Sethi, S. Waever (1995:55) argues that nothing is a security issue by itself rather it is an issue that only becomes a security issue if someone labels it as such [32]. In our contemporary world, every aspect of our live has been securitized. Whether it's a social gathering, worship, 
shopping in a mall or visit to a hospital, one has to go through security checks a thing that was not envisaged before. This theory is important in this study as it will assert the contemporary societal view of all aspects from a security perspective something that was not common a couple of years ago.

\subsubsection{Social Disorganization Theory}

Wong, C. states that Social Disorganization theory focuses on the development of high insecurity areas in which there is a disintegration of conventional values caused by rapid industrialization, increased immigration and urbanization [34]. Social disorganization theory explains why a given group in a society might turn their anger and frustrations against another group in the same society. In the wider Laikipia County, this has been the norm with armed pastoralists invading and carrying out wanton destruction of private property and lives leading to erstwhile thriving tourist destination unreachable.

\subsection{Empirical Review}

\subsubsection{CCTV and Organizational Operations}

Department of Homeland Security in U. S notes that CCTVs have various usages which include keeping property safe, providing cost-effective method of monitoring locations, providing archived video coverage for investigations and deterring against future crime attacks [9]. Security is fundamentally important across all walks of life. It ensures that the overall safety and possessions of all individuals are comprehensively protected. Cruz agrees that CCTV's are used to obtain real time and recorded visual information around facilities [6]. Ondego, O. notes that Richard Nyaga, the Chair of Kenya Alliance of Residents Association (KARA), had set the ball rolling by observing that addressing the current security challenges in Kenya requires a multifaceted approach, given the fact that the nature of crime is increasingly becoming complex and that the use of technology in finding solutions to insecurity cannot therefore be overemphasized [30].

\subsubsection{Security Service Personnel and Organizational Operations}

They form the bedrock for any security undertaking. The human element in security provision is a key factor that determines if things go right or wrong. The challenge for the State is that there are innumerable soft target areas. State agencies and public administration will never have the capacity to provide sufficient security for all possible locations. For this reason, the security measures adopted by soft targets themselves are becoming an increasingly significant component of public security. Terrorists are most likely aware of the loopholes in our country's security system, and are keen to exploit them. Corruption, poor anti-terror strategies, entrenched impunity and poor coordination agencies have emboldened terrorists to continue executing their evil plans on Kenyan soil. John L $\mathrm{H}$ notes that cross discipline training and excellent incident management is required in performance of security service duties [13].

\subsubsection{Firefighting Equipment and Organizational Operations}

Firefighting departments are anchored on their ability to prevent, protect and respond to natural and man-made disasters and other emergencies. Fire Department of New York (FDNY) identified its core competencies as fire suppression, pre-hospital emergency medical care, structural evacuation, search and rescue, arson investigation amongst other key undertakings-all of which it characterized as response-oriented [10].

Many of the core competencies that fire departments draw on in responding to, mitigating, and preventing natural or man-made disasters can be directed toward preventing terrorist incidents. In any emergency situation, Firefighters and police are regarded as the first respondents. Availability of well trained personnel and serviceable firefighting equipment is very critical in the ability of a given state to conduct a quick response. Cote $\mathrm{A}, \mathrm{E}$ notes that it is imperative that all fire service personnel are fully qualified and capable of efficiently performing of services to protect life and property. [8]

\subsubsection{Medical Facilities and Organizational Operations}

It's a vital element in any security preparedness setup. Following Sep 9/11 terror attack in U. S, Mantell noted "we do not have the capability we would need to treat the hundreds or thousands of patients that would require medical attention as a result of a large scale chemical, biological, radiological, nuclear or high yielding explosive event" [23]. Additionally, Altshuler A has observed that availability of well managed and staffed medical facilities is critical in security preparedness. [1].

\subsection{Security Preparedness and Organizational Operations}

Contemporary security challenges calls for serious measures that aims at ensuring breach of security does not occur or where it occurs, measures are taken to mitigate against the adverse effects brought about by the same. Since organizations are keen in ensuring smooth running of their day to day functions, there has been need to ensure enough time is set aside to instill conformity to set security preparedness standards. The benefits of security preparedness are insurmountable. From frisking and scanning at the entrance into a facility, to continuous monitoring by hidden cameras inside the facility, an individual feels the inherent security and the added comfort to do his business. It also creates a tradeoff between personal security and public good. For instance, not everyone feels safe being monitored from one point to another. But for the good of all, it has become necessary to monitor each and everything a person does inside all major social gatherings. Security preparedness is a multispectral discipline. It starts from an individual, community, government and private 
agencies all working towards achieving the common

good that ensures human survival and progress.

\subsection{Conceptual Framework}

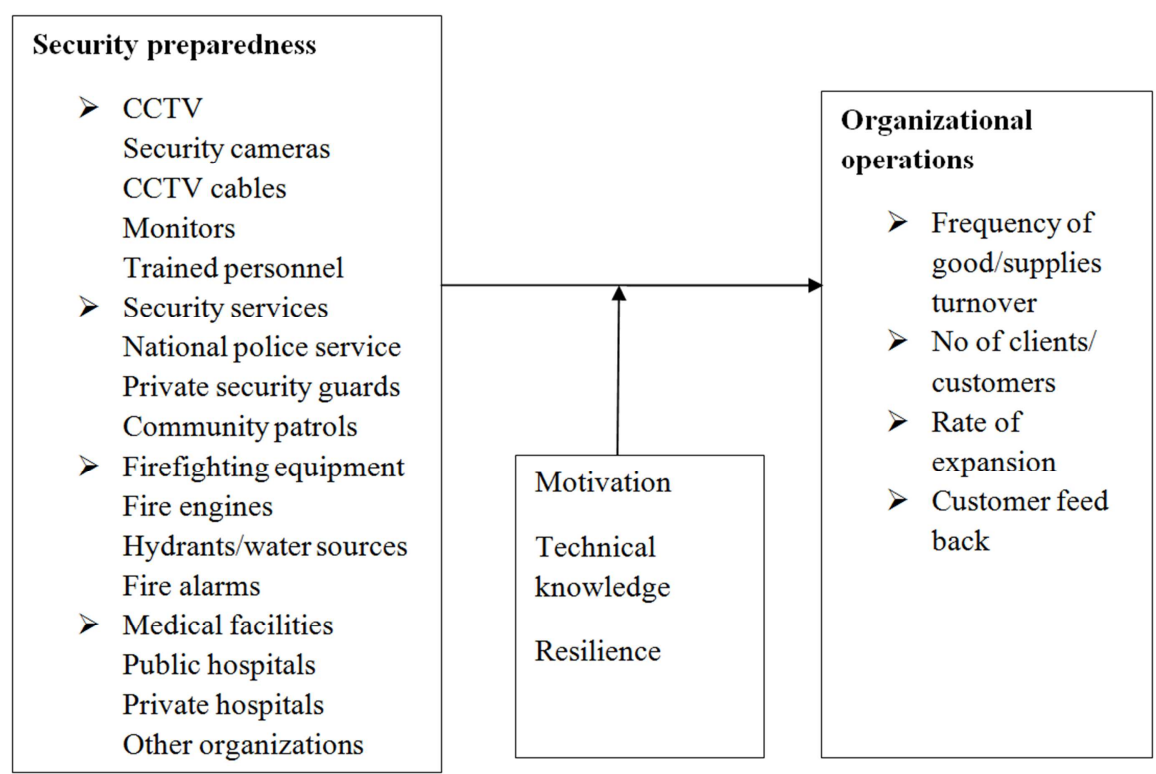

Figure 1. Conceptual Framework. Source (Author 2020).

\section{Research Methodology}

The research adopted descriptive research design. Target populations for this study were the residents of Nanyuki town, business premises and owners and institutions within Nanyuki in Laikipia County. The target population and sample size for this study was 1100 based on the institutions that were selected randomly as shown on the table 1 and 2 below. The study used descriptive research design in order to gather data with selfadministered questionnaires having structured and semistructured questions. Interview schedules were also used to gather primary data. The researcher administered the questionnaires via drop and pick method. The information on the research instrument was cross checked, inspected and scrutinized to ensure accuracy, relevance, completeness, consistency and uniformity of the collected data. To avoid errors and improve reliability, accurate coding was ensured and interviewer's bias was discouraged. This was tested through Cronbach alpha statistic and level 0.7 was considered the most appropriate. The collected data was analyzed using SPSS (Statistical Package for Social Sciences). It was presented in pie charts, bar charts and graphs. Descriptive statistics such as mean, mode, median were used. As for qualitative data, various relationships between variables were identified and the main themes derived and then summarized into short notes including quotations from key respondents, while quantitative data was used to analyze the relationship of the independent variables to the dependent variables using the regression equation shown below:

$$
\mathrm{Y}=\mathrm{a}+\mathrm{b}_{1} \mathrm{x}_{1}+\mathrm{b}_{2} \mathrm{x}_{2}+\mathrm{b}_{3} \mathrm{x}_{3}+\mathrm{b}_{4} \mathrm{x}_{4}+\mathrm{e}
$$

Where

$$
\begin{aligned}
& Y=\text { Organization operations } \\
& a=\text { Constant } \\
& b_{1}=\text { Coefficient } \\
& x_{1}=\text { CCTV } \\
& x_{2}=\text { Security services } \\
& x_{3}=\text { Firefighting equipment } \\
& x_{4}=\text { Medical facilities } \\
& e=\text { Error }
\end{aligned}
$$

Table 1. Target population.

\begin{tabular}{lll}
\hline Organization type & $\begin{array}{l}\text { Total number of } \\
\text { organizations }\end{array}$ & $\begin{array}{l}\text { Target } \\
\text { population }\end{array}$ \\
\hline Hotels & 12 & 300 \\
Shopping Malls & 2 & 400 \\
Learning Institutions & 3 & 200 \\
Medical Facilities & 2 & 200 \\
Total & 19 & 1100 \\
\hline
\end{tabular}

Table 2. Sampling design and sample size.

\begin{tabular}{llll}
\hline Organization type & $\begin{array}{l}\text { Total number of } \\
\text { organizations }\end{array}$ & $\begin{array}{l}\text { Target } \\
\text { population }\end{array}$ & $\begin{array}{l}\text { Sample } \\
\text { size }\end{array}$ \\
\hline Hotels & 12 & 300 & 30 \\
Shopping Malls & 2 & 400 & 40 \\
Learning Institutions & 3 & 200 & 20 \\
Medical Facilities & 2 & 200 & 20 \\
Total & 19 & 1100 & 110 \\
\hline
\end{tabular}

\section{Findings Presentations and Data Analysis}

\subsection{Response Rate}

The research administered 110 questionnaires to persons living or working within Nanyuki town in Laikipia County 
who had been sampled by the researcher. A total of 110 respondents responded representing $100 \%$ return rate.

\subsection{Reliability Test}

The researcher conducted a Cronbach's alpha reliability test for reliability. The study results for Cronbach's alpha indicated a 0.84925 which is way above the minimum acceptable level of 0.70 as used in social sciences. This value $(0.84925)$ implies that the instrument used measures the same construct as it has a high internal consistency as shown in table 3 below.

Table 3. Cronbach's alpha reliability test of internal consistency.

\begin{tabular}{lll}
\hline Variable & Cronbach's alpha & Number of items \\
\hline CCTV & 0.893 & 5 \\
Security Service Personnel & 0.763 & 5 \\
Fire Fighting Equipment & 0.952 & 5 \\
Medical Facilities & 0.789 & 5 \\
Average & 0.84925 & 5 \\
\hline
\end{tabular}

\subsection{Demographic Findings}

A total of 110 respondents participated in the survey of which $61(55 \%)$ were male whereas $49(45 \%)$ were female. Of the total respondents $64(58 \%)$ had their highest level of education as Undergraduate level whereas only $2(2 \%)$ had Primary education level. Larger portion of them were aged between 19-36 years represented by 84 (74.6\%). The details were broken down as follows.

\subsubsection{Respondents Gender}

The frequency table below depicts the distribution of the respondents in terms of gender. From the table, it can be deduced that the majority of the respondents were male $(55 \%)$ as compared to their females counterparts $(45 \%)$ an indication of traditional society gender biasness or a possibility of the unwillingness of the female not comfortable discussing matters security that has for long been a male domain.

Table 4. Respondents gender.

\begin{tabular}{lll}
\hline Gender & Frequency $\mathbf{( N = 1 1 0 )}$ & Percentage $\mathbf{( \% )}$ \\
\hline Male & 61 & 55.0 \\
Female & 49 & 45.0 \\
Total & 110 & 100.0 \\
\hline
\end{tabular}

\subsubsection{Respondents Education Levels}

On literacy levels, a majority of the respondents had their highest level of education at undergraduate level which clearly indicates that the governments' campaign to raise literacy levels is bearing fruits even in Laikipia County. Equally important was the fact that majority of the respondents could read and interpret the questions with ease with minimal assistance from the researcher a factor that helped save on time.

Table 5. Respondents Educational Levels.

\begin{tabular}{lll}
\hline Level of Education & Frequency $(\mathbf{N}=\mathbf{1 1 0})$ & Percentage $\mathbf{( \% )}$ \\
\hline Primary & 2 & 1.8 \\
Secondary & 36 & 32.7 \\
Undergraduate & 64 & 58.2 \\
\hline
\end{tabular}

\begin{tabular}{lll}
\hline Level of Education & Frequency $(\mathbf{N}=\mathbf{1 1 0})$ & Percentage $(\%)$ \\
\hline Masters & 8 & 7.3 \\
Total & 110 & 100 \\
\hline
\end{tabular}

\subsubsection{Respondents Age}

A bigger portion of the study population was in the age bracket of 19-36. Data from Kenya Bureau of Statics (KBS) indicates that population in the country is concentrated between the age of $15-24(19.5 \%)$ and $25-54$ (33.91\%). Kenya Age Structure, [16]. This is a clear representation of the national figures of age distribution. Further, Nanyuki town being an urban town replicates the national picture of youthful generation moving to urban areas in search of jobs to uplift their living standards.

Table 6. Respondents Age.

\begin{tabular}{lll}
\hline Age & Frequency $(\mathbf{N}=\mathbf{1 1 0})$ & Percentage (\%) \\
\hline $0-18$ & 1 & 0.9 \\
$19-36$ & 84 & 76.4 \\
$37-54$ & 24 & 21.8 \\
Beyond 54 & 1 & 0.9 \\
Total & 110 & 100 \\
\hline
\end{tabular}

\subsubsection{Respondents Domicile}

Majority of the respondents $99.1 \%$ (109) were residents of Nanyuki town while $0.9 \%$ (1) were non-residents. Whereas the researcher did not discriminate the respondents on area of residence, majority of the respondents who were residents seemed to have a upper hand in tackling the questions pertaining to organizational operations in Nanyuki town vis a vis the key variables of the study.

Table 7. Respondents Domicile.

\begin{tabular}{lll}
\hline Resident & Frequency $(\mathbf{N}=\mathbf{1 1 0})$ & Percentage (\%) \\
\hline Yes & 109 & 99.1 \\
No & 1 & 0.9 \\
Total & 110 & 100 \\
\hline
\end{tabular}

\subsubsection{Respondents Length of Stay in Laikipia}

On length of stay, majority of the respondents had stayed within Laikipia County for more than five years $46.4 \%$ (51), 3-5 years $16.4 \%$ (18), $1-3$ years $20.9 \%$ (23) and 3 months- 1 year $15.5 \%$ (17). The research targeted those who had stayed in Nanyuki town Laikipia County for an extended period of at least three (3) months and beyond. The results of the study indicated that a majority of the respondents had stayed in Laikipia County for periods longer than five years common phenomenon with the Kenyan rural set ups where people tend to stick within their areas of domicile as long as there are enough resources to cater for their needs.

Table 8. Demographics by length of stay in Laikipia.

\begin{tabular}{lll}
\hline Length of Stay & Frequency $(\mathbf{N}=\mathbf{1 1 0})$ & Percentage $(\%)$ \\
\hline 3 Months -1 yr & 17 & 15.5 \\
$1-3$ yrs & 23 & 20.9 \\
3-5 yrs & 18 & 16.4 \\
More than 5 yrs & 51 & 46.4 \\
Total & 109 & 99.1 \\
Missing & 1 & 0.9 \\
Total & 110 & 100 \\
\hline
\end{tabular}




\subsubsection{Respondents Occupation}

Thirty percent $30.9 \%$ (34) of the respondents were not engaged in gainful undertakings while a bulk of the respondents $69.1 \%$ (76) comprised a segment of population that was engaged gainfully. The study's findings on occupation were fairly encouraging with a large proportion of respondents engaging in profitable undertakings. From informal business set ups in jua kali, hawking and market stalls commonly referred to as vibanda to large complex malls strategically located within Nanyuki town ensured majority of Nanyuki town residents remained occupied.

\begin{tabular}{lll}
\hline Occupation & Frequency & Percent \\
\hline Pastor & 2 & 1.8 \\
Pharm technician & 1 & 0.9 \\
Procurement officer & 1 & 0.9 \\
Receptionist & 2 & 1.8 \\
Red cross volunteer & 1 & 0.9 \\
Secretary & 1 & 0.9 \\
Security & 5 & 4.5 \\
Student & 5 & 4.5 \\
Teacher & 3 & 2.7 \\
Tutor & 2 & 1.8 \\
Total & 110 & 100.0 \\
\hline
\end{tabular}

Table 9. Demography by occupation.

\begin{tabular}{lll}
\hline Occupation & Frequency & Percent \\
\hline Unemployed & 34 & 30.9 \\
Accountant & 2 & 1.8 \\
Administrator & 2 & 1.8 \\
Assistant manager & 1 & 0.9 \\
Business person & 22 & 20.0 \\
Clerk & 2 & 1.8 \\
Clinical pharmacist & 1 & 0.9 \\
Customer care & 1 & 0.9 \\
Director & 1 & 0.9 \\
Doctor & 3 & 2.7 \\
Farmer & 4 & 3.6 \\
H. R & 2 & 1.8 \\
Self employed & 4 & 3.6 \\
Manager & 3 & 2.7 \\
Masonry & 1 & 0.9 \\
Mechanic & 1 & 0.9 \\
Nurse & 3 & 2.7 \\
\hline
\end{tabular}

\subsection{Descriptive Findings}

\subsubsection{CCTVs and Organizational Operations}

\section{i. CCTV Role in Organizational Operations}

CCTV plays a critical role in organizations operations. This is according to the views of the respondents who were contended that its role is advancement towards security preparedness of an organization. 93\% (102) of the respondents were in agreement that its role shouldn't be neglected and viewed it as critical as opposed to the 7\% (8) who were of contrary opinion. In a study conducted in South Korea in 2012, Park et al notes that the results showed that the crime prevention effects of the CCTV were significant. The number of robberies and thefts in the areas with CCTV installed reduced by $47.4 \%$, while the areas without CCTV showed practically no change in the number of crimes [31].

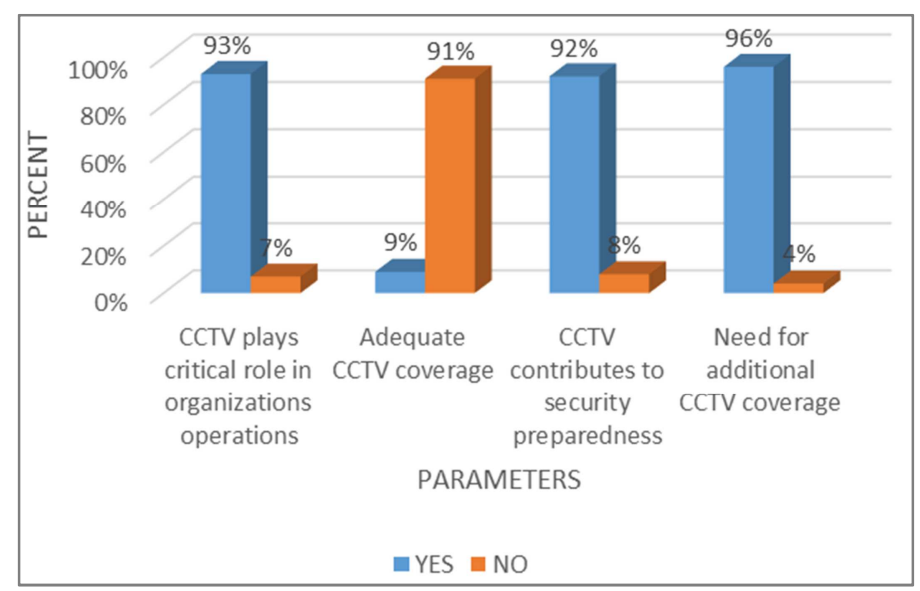

Figure 2. Respondents Views on CCTV.

\section{ii. Adequate CCTV Coverage}

CCTV coverage is inadequate in Nanyuki town according to $91 \%$ (100) of the total respondents. Only $9 \%$ (10) were satisfied with the current CCTV coverage in the town. CCTV cameras observes $\mathrm{Ng}$ 'ang'a, $\mathrm{K}$, are installed for 3D purposes (detection, deterrence and deniability/ defeatability) to unravel a criminal act about to happen or happening, to prevent the criminal act from happening or continuing and to help apprehend the culprits [28]. Alois, S and Michael, Z observes that crime reduction benefit of CCTV extend beyond the areas directly monitored by cameras (referred to as a "diffusion of benefits"). This can happen if potential offenders are aware of the presence of CCTV but unaware of its capabilities or the covered range [2].

\section{iii. Contribution of CCTV to Organizational Operations}

92\% (101) acknowledged that CCTV contributes to security preparedness in an organization as opposed to $8 \%$ (9) who were of a different view. The multiplier effect of CCTV helps keep an eye and record of activities within an organization. This in effect 
heightens their deterrence effect hence enhancing security preparedness and organizational operations. Rather than attempting to tackle crime by investing in the treatment and rehabilitation of offenders, Cohen, $\mathrm{S}$ notes that the discourse of "new behaviorism" of which CCTV surveillance is part, is less interested in the causes of crime rather than with the more modest aim of "changing behavior sequences" [7]. Arising from this it can be affirmed that if CCTV "works" by reducing crime, it works at the level of deterrence and not at the level of causation. That notwithstanding, CCTVs have been cited for promoting a false sense of security leading citizens to take fewer precautions. The above evidence presupposes that CCTV plays their intended role in security preparedness and organizational operations. But that has not always been the case. Additionally, Alois, $\mathrm{S}$ and Michael, $\mathrm{Z}$ agree that at times, targets under camera surveillance might become more and not less attractive if terrorist aspire media [2]. In such instances, the effectiveness of
CCTVs will be counterproductive.

\section{iv. Need for Additional CCTV Coverage}

$96 \%$ (106) of the respondents were of the opinion of a need for additional coverage of CCTV in Nanyuki town as a partly figure of $4 \%$ (4) see no importance of additional coverage. CCTV offers permanent, exhaustive and omnipresent surveillance whenever installed. They have a multiplier effect to other security parameters put in place bringing forth an integrated security solution to organizational operations. The draft National CCTV Policy observes that the increased level of crime in public places has necessitated various institutions and individuals, both public and private, to use CCTV as a tool to address security challenges. Increasing CCTV coverage within Nanyuki town will in essence ensure that residents demonstrate positive response to safer environment that offer additional security to their family and friends while enhancing organizational operations.

Table 10. Contribution of CCTV to organizational operations.

\begin{tabular}{|c|c|c|c|}
\hline & Agree & Neutral & Disagree \\
\hline CCTV's have an effect on organization operations & $83 \%$ & $7 \%$ & $10 \%$ \\
\hline Reduced chances of insecurity & $86 \%$ & $6 \%$ & $8 \%$ \\
\hline Increased organization operations & $72 \%$ & $18 \%$ & $10 \%$ \\
\hline Deter would be offenders & $53 \%$ & $22 \%$ & $25 \%$ \\
\hline Enhanced confidence of residents & $58 \%$ & $15 \%$ & $27 \%$ \\
\hline CCTV is a critical tool in countering modern crimes & $75 \%$ & $10 \%$ & $15 \%$ \\
\hline Need to make it mandatory for organizations to have CCTV coverage & $86 \%$ & $8 \%$ & $6 \%$ \\
\hline
\end{tabular}

Eighty three percent $83 \%$ (91) agreed that CCTV have an effect on organizations operations. This is in contrast to $10 \%$ (11) who do not believe that they have any effect. CCTV has reduced chances of insecurity, increased organizations operations, deterred would be offenders and enhanced confidence of residents of Nanyuki town according to the respondents. CCTV is a critical tool in countering and combating modern crimes according to $75 \%$ (83) of the respondents and hence a dire need to make it mandatory for organizations to have CCTV coverage which was collaborated by $86 \%$ (95) of the respondents. Okere, S recommends that building designs should be designed to incorporate the use of CCTV especially the canopies at the entrance of buildings and the design of the pedestrian pathways to effectively monitor these spaces [29].

\subsubsection{Fire Fighting Equipment and Organizational Operations}

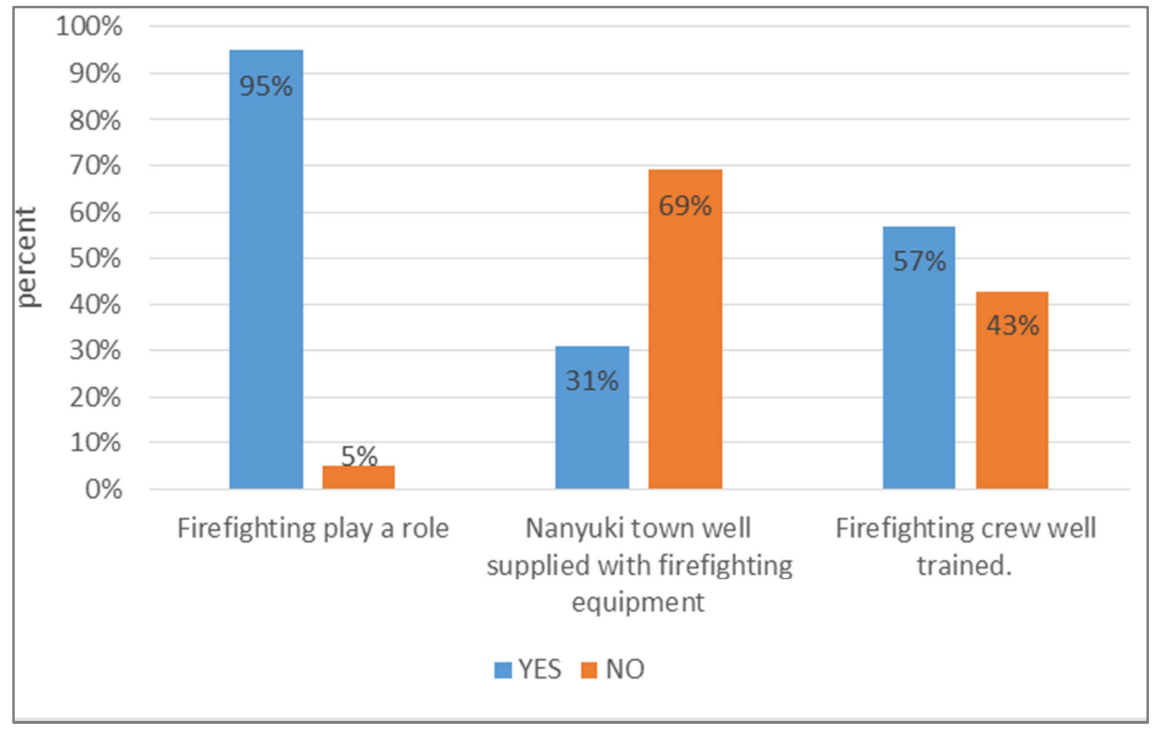

Figure 3. Respondents views on firefighting equipment. 


\section{i. Firefighting Equipment Roles in Organizational Operations}

Ninety five 95\% (105) of the respondents stated that firefighting equipment are necessary towards security preparedness and organizational operations. This was contrary to $5 \%$ (5) who were of a differing opinion. Kenya Engineer notes that the situation in Kenya is that between the year 2010 and 2014, more than one hundred fire incidents involving public buildings from across the country in which property of immense value was destroyed were reported to the ministry/state department of public works [17]. The figure may not represent the actual figures because several fire incidents go unreported. As such, organizations stand to reap much by having serviceable and well supplied firefighting equipment within their reach whenever there is a fire incident outbreak.

\section{ii. Supply of Fire-fighting Equipment Within Nanyuki \\ Town}

Sixty nine percent $69 \%$ (76) of the respondents felt that Nanyuki town does not have an adequate supply of firefighting equipment while $31 \%$ (34) were satisfied with the available equipment. Menya, A. L, notes that Kenya has no comprehensive fire disaster management policy. The draft national disaster management policy does not comprehensively cover fire disasters [24]. This is a critical omission that does not do any good to efforts of establishing serious fire departments within counties that can counter any terror related incident. Availability of adequate firefighting equipment and well trained firefighting crew is an important advantage to organizational operations.

\section{iii. Fire-fighting Crew Training}

Firefighters are believed to be well trained by $57 \%$ (63) of the respondents while only $43 \%$ (47) agree that they are not well trained. Cote A. E, notes that it is imperative that all fire service personnel are fully qualified and capable of efficiently performing the wide range of service necessary to protect life and property [8]. Ability to assemble a well-organized and trained fire crew contributes immensely to containment of fire outbreak incident. Firefighting training is an area that needs a multi sector approach since the basic techniques needs to be imparted to citizens at a much earlier stage probably to be included in the curriculum for primary school goers.

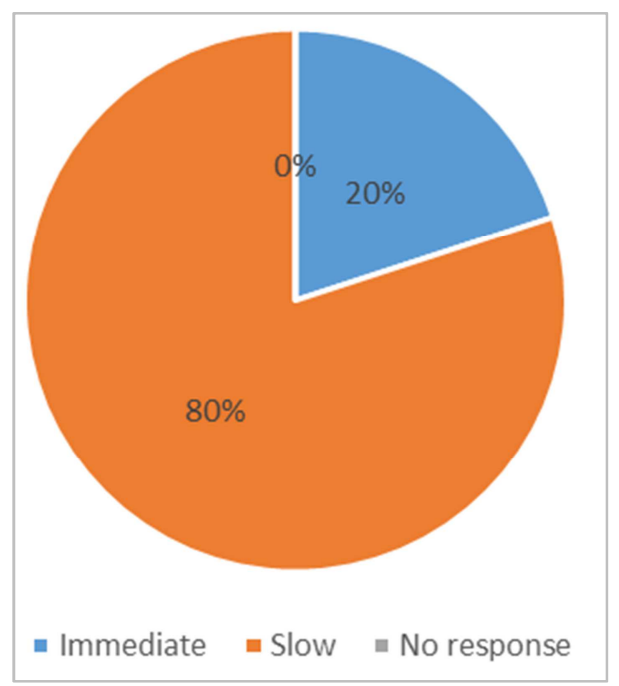

Figure 4. Level of response by fire fighters.

\section{iv. Level of Response by Firefighters}

The study revealed that $80 \%(88)$ of the respondents were in agreement that the fire fighters arrive late when called upon and not on time. Twenty percent 20\% (22) appreciated that they responded on time. Glaringly no one thought that they don't respond at all. With $80 \%$ of the respondents agreeing that fire services arrive late, it is important to add that according to National Fire Protection Association (NFPA), fire departments capability, as a measure of the ability of fire fighters to respond, mitigate and recover from each emergency call, often depends on the time of dispatch, arrival of first responders and the assembly of an effective response force in relation to magnitude of the risk event when they occur [27]. Many establishments were found not to have accessible fire assembly points which is a major requirement for building approvals in addition to hydrants for use in case of fire incident. A combination of such factors will certainly lead to poor response by the firefighting crew.

Table 11. Respondents views on firefighting equipment.

\begin{tabular}{|c|c|c|c|}
\hline & Agree & Neutral & Disagree \\
\hline Distribute firefighting equipment fairly within county & $95 \%$ & $2 \%$ & $3 \%$ \\
\hline Increase number of firefighting equipment & $96 \%$ & $1 \%$ & $3 \%$ \\
\hline All organizations to be firefighting capability compliant & $95 \%$ & $1 \%$ & $4 \%$ \\
\hline
\end{tabular}

\section{v. Respondents Views on Firefighting Equipment}

The respondents were of the opinion that firefighting equipment be distributed fairly within the county corresponding to $95 \%$ (104). $3 \%$ (3) were not in agreement while $2 \%$ (2) were neutral. Laikipia County is expansive and to assume that the whole county can be served by firefighting equipment stationed at County headquarters in Nanyuki is a lie. The need to decentralize fighting equipment as supported by $95 \%$ of the respondents is quite in order noting the poor road networks and the distance from Nanyuki town to other towns within the County.

Those of the opinion of the need to increase the number of firefighting equipment were 96\% (106). 1\% (1) was neutral while $3 \%$ (3) disagreed. Having an adequate number of firefighting equipment enhances the ability to contain fire incidents whenever they arise. 
The study further revealed that 95\% (104) of the respondents were of the view that all organizations should be compliant with firefighting capability. 1\% (1) was neutral while $4 \%$ (4) disagreed. There can be no better water way to enhance organizational operations than to have all establishments having the ability to fight fire outbreak.
Majority of outlets were found to be lacking the basic fire extinguisher that is a requirement in law within their business establishments. Those that had were not even sure any of the employee could comfortably use the fire extinguisher comfortably hence the need to enforce compliance.

Table 12. Contribution of Firefighting equipment to Organizational Operations.

\begin{tabular}{|c|c|c|c|}
\hline & Agree & Neutral & Disagree \\
\hline Response time by firefighting service providers had an impact on organization operations & $87 \%$ & $6 \%$ & $7 \%$ \\
\hline Trained fire fighters are critical to organization operations & $88 \%$ & $8 \%$ & $4 \%$ \\
\hline Number of available and serviceable firefighting equipment have an impact on organization operations & $86 \%$ & $9 \%$ & $5 \%$ \\
\hline Accessibility of location of locations impacts on effectiveness of firefighting equipment & $89 \%$ & $4 \%$ & $7 \%$ \\
\hline
\end{tabular}

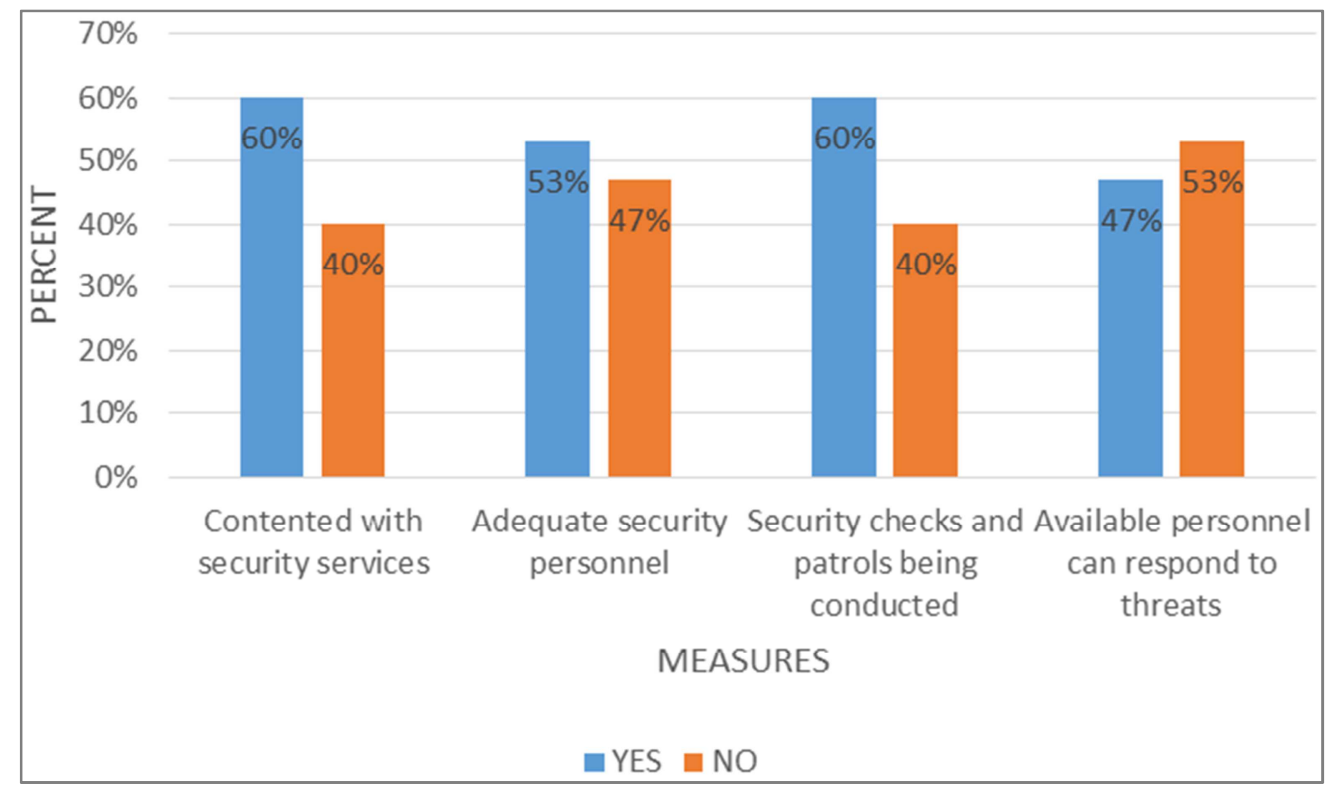

Figure 5. Respondents opinion on security service providers.

\section{vi. Contribution of Firefighting Equipment to Organizational Operations}

Several factors that have an impact on how firefighting affects organizational operations were considered in order to determine the role it plays in organizational operations. From the above results, $87 \%$ (96) were of the opinion that response time by firefighting service providers had an impact on organizational operations. $88 \%$ (97) of the respondents agree that trained fire fighters are critical in organizational operations. 8\% (9) were neutral while 4\% (5) disagreed. 86\%

\subsubsection{Security Service Providers and Organizational Operations}

\section{i. Respondents Contentment with Security Service}

Sixty percent $60 \%$ (66) of the respondents were satisfied with the security services within Nanyuki town. $40 \%$ (44) of the respondents were not contented with the security service. Security service providers play a critical role in organizational operations. They range from privately hired guards, community patrol unit to police service. The role of other uniformed personnel within Nanyuki town is minimal aside from the deterrence nature their presence offers.
(95) of the respondents were of the opinion that the number of available and serviceable firefighting equipment had an impact on organization operations. On the other hand, $89 \%$ (98) of the respondents believe that accessibility of locations impacts on effectiveness of firefighting equipment with a partly figure of $4 \%$ (5) and 7\% (7) being neutral and in disagreement respectfully. The Kenya Commission of Red Cross, observes Kenya Engineer, attributes increase of fire incidences to overcrowding in informal settlements, lack of access roads and firefighting services among others [17].

Such confidence is important as it contributes positively to organizational operations within Nanyuki town.

\section{ii. Adequacy of Security Personnel}

$53 \%$ (58) agreed that the number of security personnel is adequate while $47 \%$ (52) saw the need to increase the number. Over half of the respondents aver that available security personnel are adequate which points to the confidence the residents have in conducting their day to day businesses. Effective policing and maintenance of law and order in expansive towns like Nanyuki requires large numbers of security personnel to adequately cover all the 
corners of the town.

\section{iii. Security Checks and Patrols Conducted}

$60 \%$ (66) of the respondents agree that security checks and patrols conducted were adequate to deter any possible threat while $40 \%$ (44) were of a contradicting opinion. Nanyuki town lies strategically along a busy highway and security checks while entering and leaving the town plays a major role in filtering bad human traffic getting in and out of the town. The study revealed that majority of the residents agrees the measures put in place were adequate to deter any possible threat which is an added advantage to organizational operations.

\section{iv. Available Personnel and Response to Threats}

On the issue concerning whether the available personnel can respond to the security threats in case of need, 53\% (58) believe that they were not able to do so as $47 \%$ (52) were of the contrary opinion. Ability to adequately respond to a threat combines several factors among them the time the security service providers are called in, distance to the location of the incident, road networks and availability of means to convey security service provides to the scene. That over half of the respondents believe that the available personnel cannot respond to a security threat adequately is not good for organizational operations in Nanyuki town.

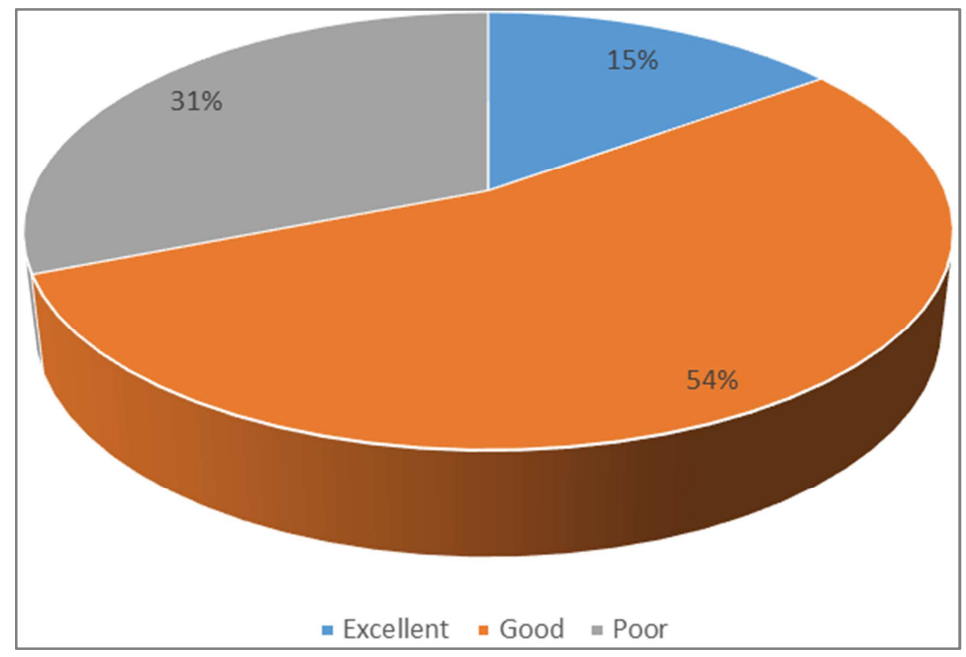

Figure 6. Respondents view on security service providers.

\section{v. Respondents View on Security Service Providers}

More than half 54\% (57) of the respondents agree that the responsiveness of security personnel is good whereas $31 \%$ (33) were of the view that that it was poor. $15 \%$ (16) rated the response they get as excellent. The response time by security agents to terror incidents strikes a balance between what is lost and what is rescued in a terror attack. Maluki M. P asserts that during the Dusit attack at Riverside in Nairobi on 15 Jan 19, the attack could have gone down as one of the worst in modern Africa history were it not for the fact that security apparatus sprang into action with amazing speed [22]. Failure to implement the security bill that could have armed private security guards has been an impediment to reaction to terror incidences.

Table 13. Security Service providers and Organizational Operations.

\begin{tabular}{|c|c|c|c|c|c|}
\hline & Strongly Agree & Agree & Neutral & Disagree & Strongly Disagree \\
\hline & $\%$ & $\%$ & $\%$ & $\%$ & $\%$ \\
\hline Personnel have inadequate training & 2 & 36 & 26 & 26 & 9 \\
\hline Personnel have low standard drills & 26 & 63 & 7 & 0 & 5 \\
\hline Inadequate response time & 11 & 39 & 28 & 17 & 5 \\
\hline Inadequate gadgets & 30 & 32 & 19 & 14 & 5 \\
\hline Personnel are lowly motivated & 43 & 30 & 12 & 9 & 6 \\
\hline Lack of information sharing hampers organization operation & 50 & 26 & 9 & 6 & 4 \\
\hline Too many uniformed men leads to laxity & 27 & 21 & 25 & 16 & 8 \\
\hline
\end{tabular}

\section{vi. Security Service Providers and Organizational Operations}

A simple frequency table was used to illustrate the results from the respondents. This depicts their percentage distribution on various ratings. $36 \%$ (38) of the respondents are in agreement that security personnel have inadequate training. Those who rated neutral and disagreed were both at $26 \%$ (28) while $9 \%$ (10) strongly disagreed and 2\% (2) strongly agreed. John, L. H notes that integrated, rapid, law-enforcement directed response have a potential to save many lives, but cross-discipline training and excellent incident management 
and coordination is required to safely perform this response [12]. Accordingly, there is urgent need to tailor the training of security service providers to contemporary security threats if they are to counter emerging threats.

Sixty three (63\%) (67) of the respondents agree that security service personnel have low standard drills for security preparedness. $26 \%$ (27) strongly agree that there are low standard drills for security personnel while 7\% (7) are neutral and 5\% (5) strongly disagree. Thirty nine percent (41) agree that security service personnel have inadequate response time closely followed by those who rated neutral at $28 \%$ (29) while $11 \%$ (12) strongly agree and 5\% (5) strongly disagree. Concerning inadequacy of security gadgets, 32\% (34) agree that security service personnel do not have adequate security gadgets while $30 \%$ (31) strongly agreed. $19 \%$ (20) were neutral while $14 \%$ (15) disagreed and 5\% (5) strongly disagreed. On the aspect of low personnel motivation, 43\% (46) were in agreement while $30 \%$ (31) strongly agreed. 12\% (13) were neutral while $9 \%(9)$ and $6 \%$ (6) disagreed and strongly disagreed that security service personnel were lowly motivated to deliver service.

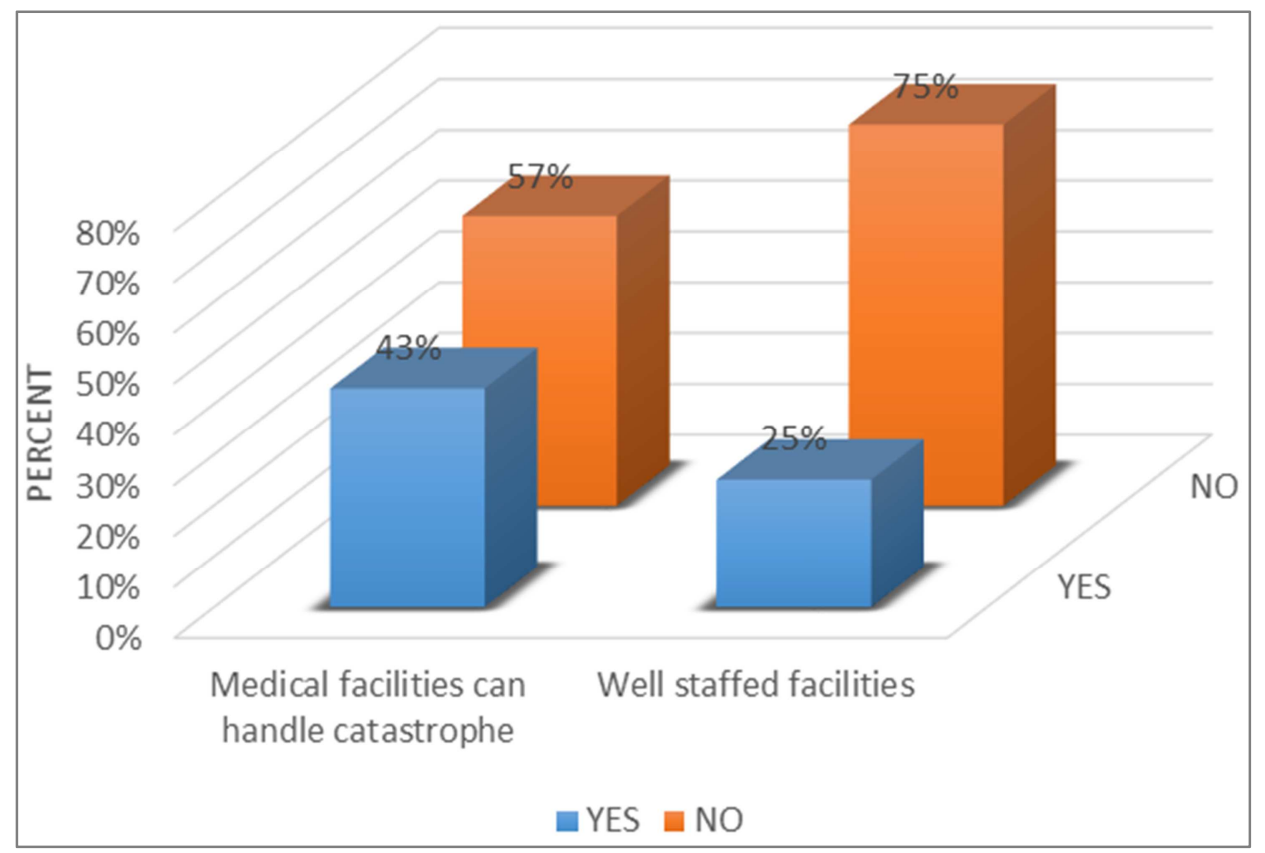

Figure 7. Respondents views on medical facilities and organizational operations.

On whether security service personnel available within Nanyuki are adequate for organizational operations, 51\% (46) agree, 16\% (18) strongly agree, 16\% (17) are neutral while $13 \%$ (14) and 5\% (5) disagree and strongly disagree respectively. On whether lack of information sharing among security agencies affects security preparedness and organizational operations, 50\% (55) agree while 26\% (28) strongly agree. $9 \%$ (10) were neutral while $6 \%$ (7) and $4 \%$ (4) disagree and strongly disagree respectively. Asked whether presence of too many uniformed men within Nanyuki town had led to laxity among security service providers hence affecting organizational operations, 27\% (30) agreed while 21\%(23) strongly agreed. 24\% (26) were neutral while 16\% (16) disagreed. 8\% (9) strongly disagreed with the view.

Whereas Nanyuki town boasts of a large number of security forces, majority of the respondents believe that the security forces do not have common drills that can boost their response to any eventuality. There is need to have a multiagency approach by bringing all the operational doctrines of various forces operating within Nanyuki town together.

\subsubsection{Medical Facilities and Organizational Operations}

\section{i. Ability of Medical Facilities to Handle Catastrophe}

According to the research findings, 43\% (39) believe that available medical facilities within Nanyuki can handle catastrophe of any magnitude while 57\% (62) were of the view that they cannot handle. Apart from medical facilities within military barracks, Nanyuki town has a teaching and referral hospital that is rated Level Five hospital according to the national government ratings and two private medical facilities.

\section{ii. Staffing of Medical Facilities}

$25 \%$ (26) of the respondents agree that medical facilities within Nanyuki are well staffed while $75 \%$ (83) believe that the facilities are not well staffed. The need for adequate and well-staffed medical facilities as a prelude to security preparedness and organizational operations cannot be overemphasized. John. L. H et al observes that sudden impact events that generate large numbers of casualties in a very short period of time are rare events, but when they do occur, time is of essence to reduce the number of lives lost and provide competent and coordinated care to the victims [13]. 
Leaders should identify potential recruits and train them as

terror attack. social workers to form the first line of response in case of a

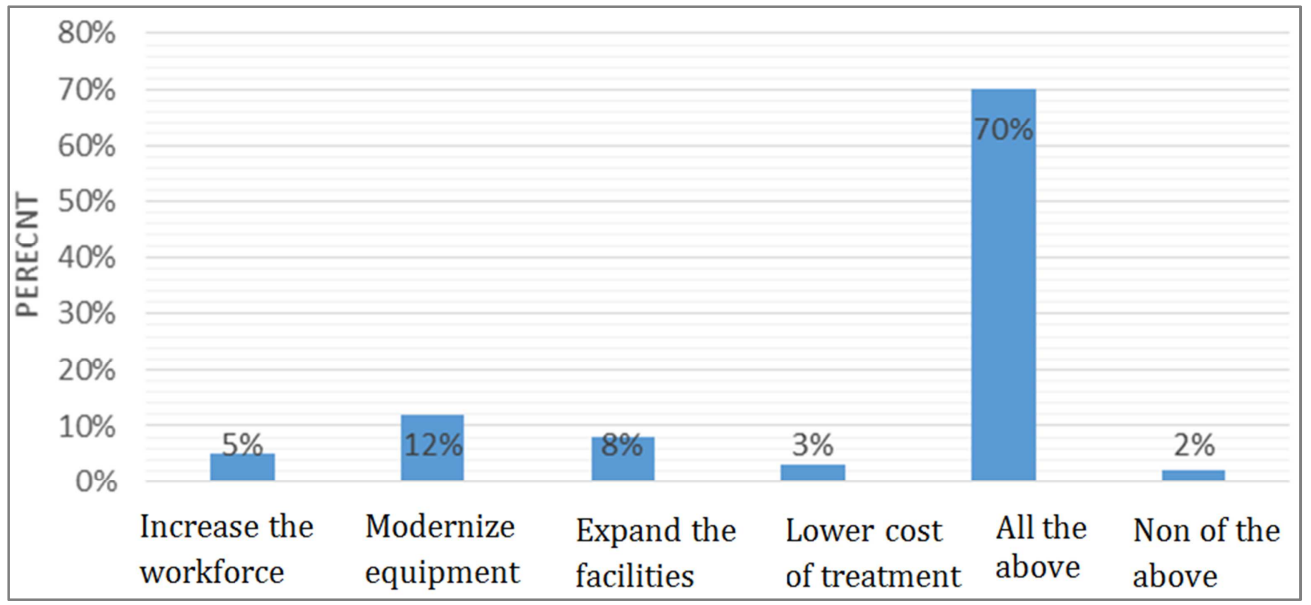

Figure 8. How to enhance the role of Medical Facilities in Security Preparedness.

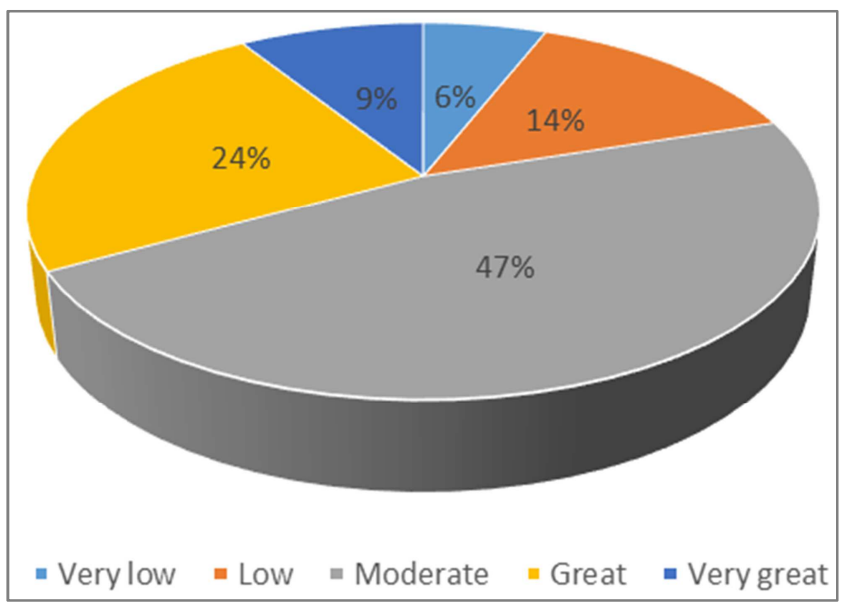

Figure 9. Extent to which Medical Facilities enhance Organization Operations.

\section{iii. Enhancing the Role of Medical Facilities}

The study also revealed that seventy percent (77) feel that to enhance security preparedness and organizational operations, there is need to increase the work force, modernize equipment, expand medical facilities, and lower cost of treatment. Only 5\% (5) felt that increasing the workforce was critical in enhancing organizational operations while $12 \%$ (13) were of the view that modernized medical equipment were vital. 8\% (9) opined that expanded medical facilities would contribute to security preparedness and organizational operations. 3\% (3) thought that lowering cost of treatment was the answer to security preparedness while $2 \%$ (2) thought that none of the statements contributed to organizational operations.

\section{iv. Extent to Which Medical Facilities Enhance \\ Organizational Operations}

When rated on a scale of 1 (very low) to 5 (very great), $(47 \%)(52)$ of the respondents believe that medical facilities enhance organizational operations moderately while $6 \%$ (7) thought that the extent to which the facilities enhance organizational operations is very low. $24 \%$ (26) believe that medical facilities enhance organizational operation to a great extent while $9 \%$ (10) thought they enhance it in a very great way. Medical facilities come in handy in case of any disruption of organizational operations hence, there is need to ensure their functions are not interrupted.

\section{v. Impact of Understaffed Medical Facilities}

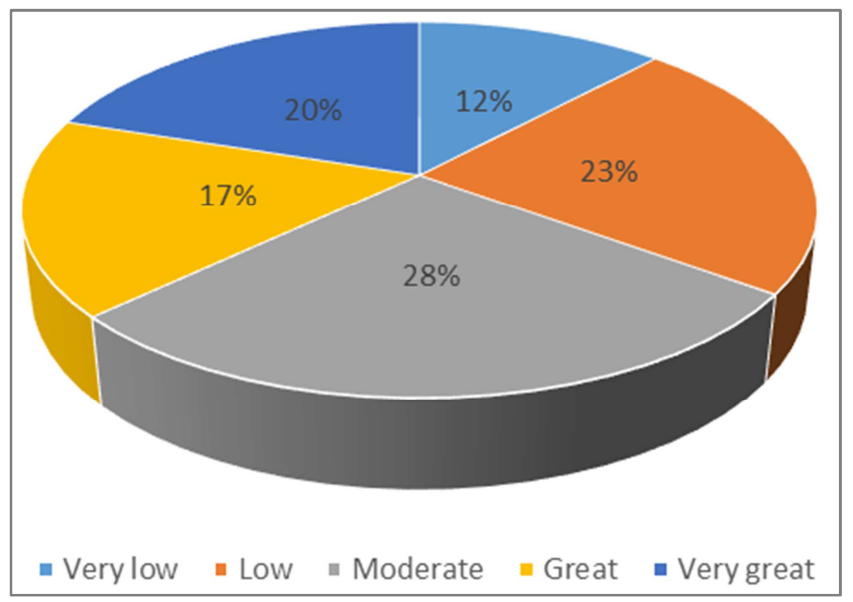

Figure 10. Impact of understaffed medical facilities on organizational operations.

The impact of understaffed medical facilities on organizational operations was taken into consideration too. The study established that on a scale of very low, low, moderate, great and very great, $28 \%$ (29) thought staffing had a moderate effect on organizational operations. 23\% (24) believe that staffing has low effect on security preparedness and organizational operations. $20 \%$ (21) of the respondents thought that its effect was very great while $17 \%$ (18) thought its effect is great. On the other hand $12 \%$ (12) observed that its effect was very low. A serious understaffing in medical facilities across the nation continues to be witnessed. 
Attendant to the understaffing, is the inability by the counties to meet medical needs for the population more so in case of a surge in the number of people requiring medical attention and emergencies.

\subsubsection{Security Preparedness}

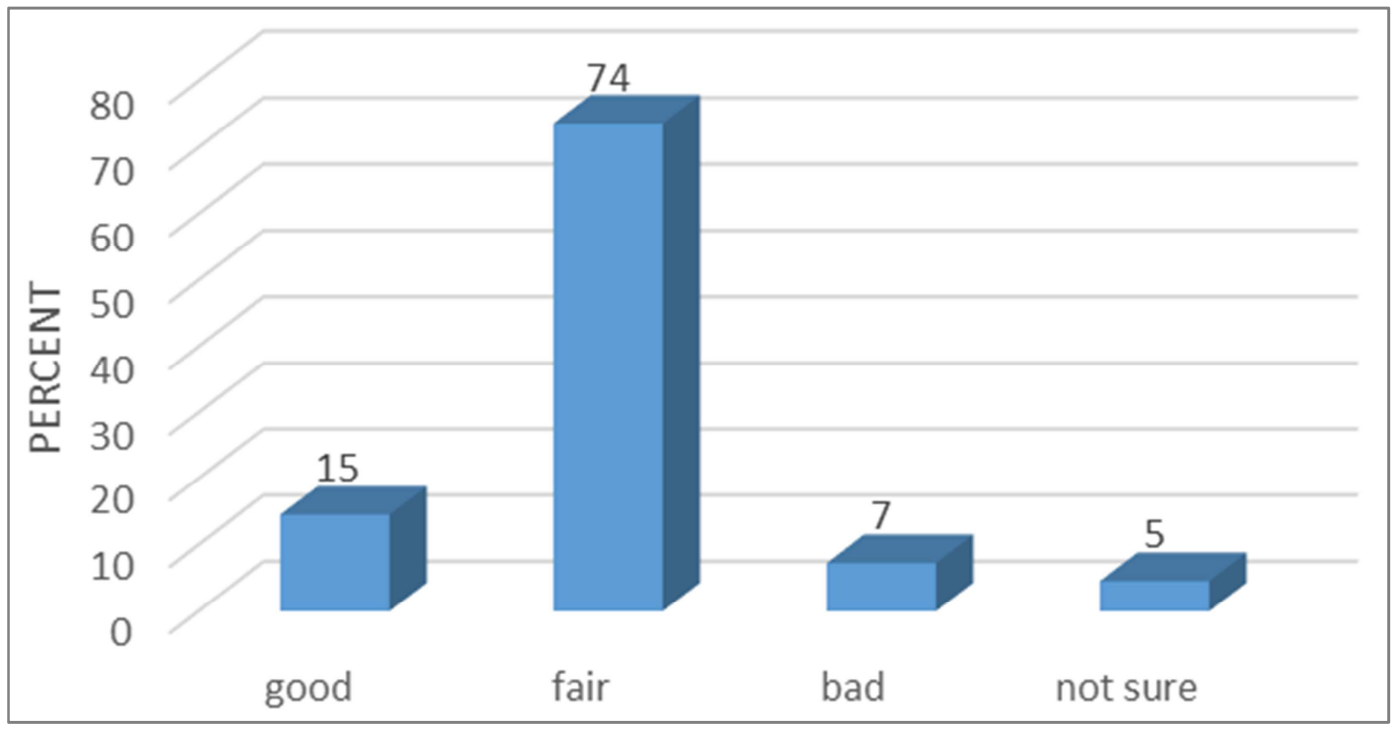

Figure 11. Security situation.

From the figure 11 above, seventy four percent $74 \%$ (81) of the respondents were of the opinion that the security situation was fair. $15 \%$ (17) rated the situation as good while those who rated it bad and not sure were $7 \%$ (8) and $5 \%$ (5) respectively. These ratings can be attributed to a couple of factors among them the response time by security personnel, number of incidents that could have been averted by the security agents, presence of the security personnel, information sharing between residents and security agencies among other factors. The response affirms some level of confidence by the population and an added advantage to organizational operations by the response of close to three quarters of the respondents who rated the situation as fair.

\subsubsection{Awareness of Security Preparedness Measures}

More than half $55 \%$ (61) of the respondents were not aware of any security preparedness measures in place as opposed to $43 \%$ (47) who were aware of the measures. $2 \%$ (2) did not have a valid decision or were unable to comment on this. The findings indicate a serious flaw on lack of campaigns to create awareness to the general public on what the county government is doing as pertains to security preparedness that goes ahead to reinforce the fact that matters security, though not devolved from the central government are not taken serious by the devolved units. Shockingly, installation of street lights and CCTV's along the streets of Nanyuki town is an obvious security preparedness measure that the respondents were not aware of.

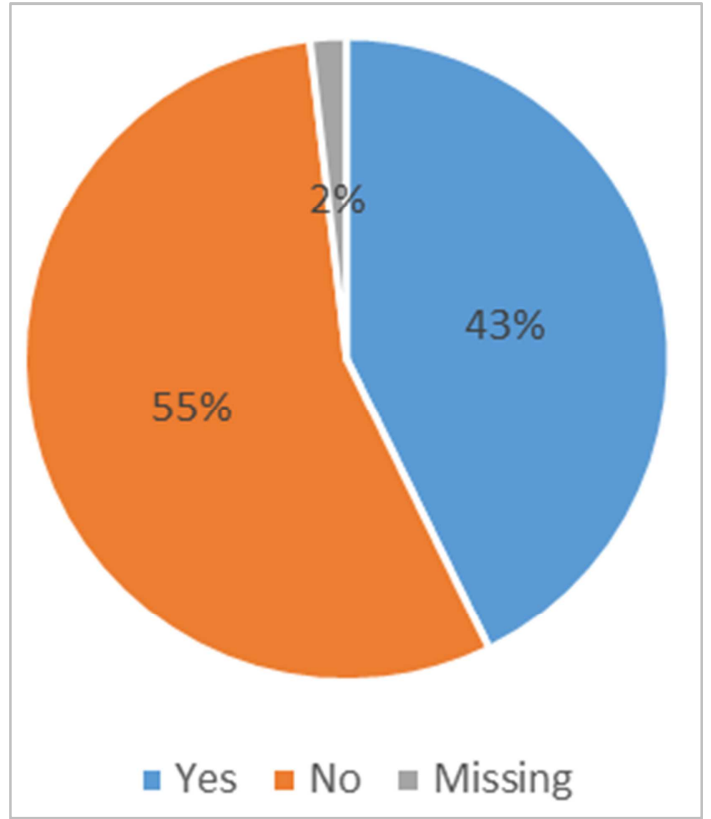

Figure 12. Awareness of Security Preparedness measures.

\subsection{Pearson Correlation}

The study conducted a correlation analysis of the variables of the study: CCTV, security service, firefighting equipment as well as medical facilities and organizational operations. The study used Karl Pearson's coefficient of correlation to quantify the strength of the relationship between the variables. A 2-tailed Pearson Correlation test was done at $99 \%$ and $95 \%$ confidence levels and the analysis presented in Table 14 below. 
Table 14. Pearson Correlation test.

\begin{tabular}{|c|c|c|c|c|c|c|}
\hline \multicolumn{7}{|l|}{ Correlations } \\
\hline & & CCTV & $\begin{array}{l}\text { Security service } \\
\text { personnel }\end{array}$ & $\begin{array}{l}\text { Firefighting } \\
\text { equipment }\end{array}$ & Medical facilities & $\begin{array}{l}\text { Organizational } \\
\text { operations }\end{array}$ \\
\hline CCTV & $\begin{array}{l}\text { Pearson Correlation } \\
\text { Sig. (2-tailed) }\end{array}$ & 1 & & & & \\
\hline $\begin{array}{l}\text { Security service } \\
\text { personnel }\end{array}$ & $\begin{array}{l}\text { Pearson Correlation } \\
\text { Sig. (2-tailed) }\end{array}$ & $\begin{array}{l}.099 \\
.301\end{array}$ & 1 & & & \\
\hline \multirow{2}{*}{$\begin{array}{l}\text { Firefighting } \\
\text { equipment }\end{array}$} & Pearson Correlation & $.287^{* *}$ & .170 & 1 & & \\
\hline & Sig. (2-tailed) & .002 & .076 & & & \\
\hline \multirow{2}{*}{ Medical facilities } & Pearson Correlation & $.203^{*}$ & .099 & .050 & 1 & \\
\hline & Sig. (2-tailed) & .033 & .303 & .606 & & \\
\hline \multirow{2}{*}{$\begin{array}{l}\text { Organizational } \\
\text { operations }\end{array}$} & Pearson Correlation & .025 & $.208^{*}$ & .012 & -.032 & 1 \\
\hline & Sig. (2-tailed) & .798 & .029 & .904 & .738 & \\
\hline
\end{tabular}

**. Correlation is significant at the 0.01 level (2-tailed).

*. Correlation is significant at the 0.05 level (2-tailed).

The results in Table 14 above indicate that there is a positive and important relationship between CCTV and organization operations $(\mathrm{r}=0.099, p<0.05)$, there is a positively significant correlation between security service personnel and organization operations in Laikipia County Kenya ( $\mathrm{r}=0.099, p<0.05)$. Further, the results indicate that there is moderate correlation between firefighting equipment and organizational operations in Laikipia County, Kenya $(\mathrm{r}=0.287, p<0.05)$. And lastly, the results indicate that there is a moderate correlation between medical facilities and organizational operations in Laikipia County Kenya $(\mathrm{r}=0.33, p<0.05)$.

\subsection{Inferential Statistics}

The study further carried out regression analysis to establish the statistical significance of the relationship between the independent variables, $\left(\mathrm{X}_{1}\right) \mathrm{CCTV},\left(\mathrm{X}_{2}\right)$ Security services, $\left(\mathrm{X}_{3}\right)$ Firefighting equipment, $\left(\mathrm{X}_{4}\right)$ Medical facilities and the dependent variable (Y) Organization operations. The regression analysis results were presented using regression model summary table, Analysis Of Variance (ANOVA) table and coefficients of variance table. The model used for the regression analysis was expressed in the general form as given below:

$$
\mathrm{Y}=\mathrm{a}+\mathrm{b}_{1} \mathrm{x}_{1}+\mathrm{b}_{2} \mathrm{x}_{2}+\mathrm{b}_{3} \mathrm{x}_{3}+\mathrm{b}_{4} \mathrm{x}_{4}+\mathrm{e}
$$

From the model depicted above, organization operations was used as the dependent variable $(\mathrm{Y})$ while, $\left(\mathrm{X}_{1}\right)$ CCTV, $\left(X_{2}\right)$ Security services, $\left(X_{3}\right)$ Firefighting equipment and $\left(X_{4}\right)$ Medical facilities as the independent variables. The relationships between the dependent variable and independent variables on one hand and the results of testing significance of the model were also interpreted. The multiple regression analysis model was interpreted using three major categories of elements: the coefficient of multiple determinations, the standard error of estimate and the regression coefficients.

Table 15. Regression Model Summary.

\begin{tabular}{lllll}
\hline Model & $\mathbf{R}$ & R Square & $\begin{array}{l}\text { Adjusted R } \\
\text { Square }\end{array}$ & $\begin{array}{l}\text { Std. Error of } \\
\text { the Estimate }\end{array}$ \\
\hline 1 & $.864^{\mathrm{a}}$ & .747 & .711 & 1.32120 \\
\hline
\end{tabular}

a. Predictors: (Constant), 4. Medical facilities, 3. Firefighting equipment, 2. Security service personnel, 1 . CCTV

$\mathrm{R}$ squared was used to check how well the model fitted the data. $\mathrm{R}$ squared is the coefficient of multiple regression that measures the proportion of variations in the dependent variable which is explained by variations in the independent variables. These elements and the results of multiple regression analysis were presented and interpreted accordingly in table 15 , table 16 and table 17 .

\subsection{Regression Model}

The study findings shown above, includes information about the quantity of variance that is explained by the independent variables (CCTV, security service, firefighting equipment and medical facilities). The first statistic, $R$, is the multiple correlation coefficients between all of the independent variables and the dependent variable. In this model, the value is 0.864 , which indicates that there is a great deal of variance shared by the CCTV, security service, firefighting equipment and medical facilities. The next value, $R$ Square, is simply the squared value of $R$. This is frequently used to describe the goodness-of-fit or the amount of variation explained by a given set of predictor variables. In this model, the value is 0.747 , which indicates that $74.7 \%$ of the variance in organization operations is explained by CCTV, security service, firefighting equipment and medical facilities, while the remaining $25.3 \%$ is explained by the variables outside the model.

Table 16. ANOVA Table ANOVA ${ }^{a}$.

\begin{tabular}{lllllll}
\hline Model & & Sum of Squares & Df & Mean Square & F & Sig. \\
\hline 1 & Regression & 1409.088 & 4 & 352.272 & 91.349 & $.000^{\mathrm{b}}$ \\
\hline
\end{tabular}




\begin{tabular}{|c|c|c|c|c|c|}
\hline Model & Sum of Squares & Df & Mean Square & $\mathbf{F}$ & Sig. \\
\hline Residual & 409.395 & 105 & 3.899 & & \\
\hline
\end{tabular}

a. Dependent Variable: 5. Organizational operations.

b. Predictors: (Constant), 4. Medical facilities, 3. Firefighting equipment, 2. Security service personnel, 1. CCTV.

Table 16 above, in the output is an ANOVA table that describes the overall variance accounted for in the model (the overall significance of the model). The $F$ statistic represents a test of the null hypothesis that the expected values of the regression coefficients are equal to each other and that they equal zero. Put another way, this $F$ statistic tests whether the $\mathrm{R}$ square proportion of variance in the dependent variable accounted for by the predictors is zero. If the null hypothesis were true, then that would indicate that there is not a regression relationship between the dependent variable and the predictor variables. In this model, the three predictor variables (CCTV, security service, firefighting equipment and medical facilities) are not all equal to each other and could be used to predict the dependent variable, organizational operations, as is indicated by a large $F$ value of 91.349 and a p-value of 0.000 which is less than alpha at 0.05 level of significant. Therefore the overall regression model is significant at $5 \% \mathrm{~F}(4,105)=91.349, \mathrm{p}<0.000, \mathrm{R}^{2}=0.747$. In other words all the independent variables significantly influenced organization operations.

Table 17. Coefficients of Variables Table Coefficients ${ }^{a}$.

\begin{tabular}{lllllll}
\hline \multirow{2}{*}{ Model } & & \multicolumn{2}{c}{ Unstandardized Coefficients } & Standardized Coefficients & \multirow{2}{*}{ T } & \\
\cline { 3 - 6 } & & B & Std. Error & Beta & & \\
\hline \multirow{2}{*}{1} & (Constant) & 2.800 & .563 & & 4.973 & .000 \\
& 1. CCTV & .037 & .166 & .023 & .226 & .002 \\
& 2. Security service personnel & .389 & .174 & .217 & 2.231 & .000 \\
& 3. Firefighting equipment & -.067 & .234 & -.029 & -.287 & .001 \\
& 4. Medical facilities & -.060 & .103 & -.057 & -.583 & .070 \\
\hline
\end{tabular}

a. Dependent Variable: 5. Organizational operations.

In table 17 above, the coefficient tells us how much the dependent variable is expected to increase when that independent variable increases by one, holding all the other independent variables constant. The multiple regression model indicates that when all the independent variables thus; $\left(X_{1}\right)$ CCTV, $\left(X_{2}\right)$ Security services, $\left(X_{3}\right)$ Firefighting equipment, $\left(\mathrm{X}_{4}\right)$ Medical facilities are to remain constant then the dependent variable $(\mathrm{Y})$ Organizational operations will change by 2.8 units. The model predicts that for an additional unit of CCTV, organization operations increases by 0.037 units holding Security services, Firefighting equipment and Medical facilities constant; for an additional unit of security services, organizational operations increases by 0.389 units holding CCTV, Firefighting equipment and Medical facilities constant; an additional unit of firefighting equipment, organizational operations decreases by 0.067 units holding CCTV, security services and medical facilities constant; an additional unit of medical facilities, organizational operations decreases by 0.060 units holding CCTV, security services and firefighting equipment constant. The resultant fitted regression function from the output in table 17 above is;

$$
Y=2.80+0.037 X_{1}+0.389 X_{2}+0.067 X_{3}+0.060 X_{4}
$$

\section{Summary of the Findings}

The study found out that organizations security preparedness entails plans of actions geared towards protecting against danger or loss with a great emphasis on protection from danger that originates from external surroundings such as human errors, processes, and technical and information technology. The study also established that the major factors that influenced organizational operations in Laikipia County are availability of CCTVs, firefighting equipment, security service providers and medical facilities.

\subsection{CCTV's}

The study findings showed that there is a positive and important relationship between CCTV and organization operations in Laikipia County. The results showed that a unit increase in CCTV leads to a 0.037 increase in organizational operations. These findings relate with the literature review where [6] explains that CCTV are used to obtain real time and recorded visual information around facilities.

\subsection{Security Service Providers}

The study found that there is a positively significant correlation between security service personnel and organization operations in Laikipia County. For an additional unit of security services, organization operations increase by 0.389 units. These findings relate with [13] who contends that cross discipline and excellent incident management and coordination is required to safely perform security service duties.

\subsection{Firefighting Equipment}

The study found that there is a moderate correlation between firefighting equipment and organizational operations in Laikipia County. For an additional unit of firefighting 
equipment, organization operations decrease by 0.067 . The findings agree with what [18] noted that it is imperative that all fire service personnel are fully qualified and capable of efficiently performing of services to protect life and property. Much of the core competencies that fire departments draw on in reacting to, alleviating and preventing natural or manmade disasters can be directed toward preventing terrorist incidents. In any emergency situation, Firefighters and police are regarded as the first respondents.

\subsection{Medical Facilities}

The study found that that there is a moderate correlation between medical facilities and organizational operations in Laikipia County. For an additional unit of medical facilities, organization operations increase by 0.389 units. These findings relate with the literature review where [1] contends that availability of well managed and staffed medical facilities is critical in security preparedness.

\section{Conclusion}

Based on the study findings, it can be overly concluded that the four variables play a key role in security preparedness and organizational operations but regrettably Nanyuki town has done little in enforcing security preparedness based on the variables.

\subsection{Recommendations}

The study recommends that the County government increases CCTV coverage within Nanyuki town with an eventual aim of connecting all CCTV's to a central police server who can monitor them centrally in addition creation of bylaws requiring all building designs to incorporate the use of CCTV's.

Firefighting equipment to be modernized, increased and be devolved within the county. Additionally, relevant training of crew that covers all pertinent issues related to specific fire disaster be passed to the fire fighters.

To be properly constituted for any terror eventuality, security agencies need to come up with incident specific Standard Operating Procedures (SOPs) that is shared among all the key players within Nanyuki and its environs. Additionally, the county to come up with functional disaster response unit with clear drawn incident command structure which will develop and implement county specific action plans.

A formal evaluation of the preparedness of medical facilities within Nayuki town for mass casualty response in case of a terrorist incident and the threat of them becoming targets of terrorist attack.

\subsection{Suggestions for Further Research}

From the findings of the study, the following areas are recommended for further research;

Whether the lackadaisical approaches to security by the counties is as a result of complacency or pull and push between the national government and county governments.

Whether statistically, crime levels have reduced with the evolution of CCTV's in major towns within the country.

Any other attribute that can contribute to security preparedness and organizational operations specific to different regions within the country.

\section{References}

[1] Altshuler, A. (2016). Israel's Emergency Management Challenge. Harvard Kennedy School.

[2] Alois S. \& Michael Z. (2013) Is camera surveillance an effective measure of counterterrorism?, Defence and Peace Economics, 24: 1, 1-14, DOI: 10.1080/10242694.2011.650481

[3] Barnett, H. (2015, Apr 04). Kenya Terror Attacks; Al-Shabbab warns cities "will turn red with blood" from more attacks. Daily Express.

[4] Buzzan, B. et al (1998). Security: A new framework for analysis. London. Lynne Rienner Publishers Boulder.

[5] Cannon, B. (2001, Sep, 12). Significance of 9/11 impact upon US foreign policy should not be overestimated, Leffler says. Washington. UVA Today.

[6] Cruz, G. M (2015). The Importance of CCTV Security Systems in Business. https://www.linkedin.com

[7] Cohen, S. (1985). Visions of social control. Cambridge. Polity Press.

[8] Cote, A. E (2003). Organizing for Fire and Rescue Services. Massachusetts. USA.

[9] Department of Homeland Security. USA.

[10] Fire Department of New York (FDNY). (2008).

[11] Gimode, Edwin A. "An Anatomy of Violent Crime and Insecurity in Kenya: The Case of Nairobi, 1985-1999." Africa Development / Afrique Et Développement, vol. 26, no. 1/2, 2001, pp. 295-335. JSTOR, www.jstor.org/stable/43661162. Accessed 3 Oct. 2020.

[12] John, L. H. et al (2016). Health and Medical Response to Active Shooter and Bombing Events. National Academy of Medicine. Discussion Paper.

[13] John, L. H. et al (2017). Health and Medical Response to Active Shooter and Bombing Events. National Academy of Medicine. Discussion Paper.

[14] Kalvach Z et al (2016). Basics of Soft Target Protection. Soft Target Protection Institute: Prague.

[15] Kenya Age Structure (2018). Nairobi. Government printer.

[16] Kenya Engineer (Nov, 20, 2017). Managing Fire Disasters: Evaluating the Effectiveness of Fire Safety Training on Occupants Response to Fire in Selected Public Buildings in Nairobi County, Kenya. https://www.kenyaengineer.co.ke

[17] Kenya Information Guide (2017). Nairobi. Government Printer.

[18] Langat, A. (2016, Dec, 27). Why Kenya's cattle raids are getting deadlier. Aljazeera.

[19] La Tourrette, T. et al (2006). Reducing terrorism at shopping centres: An analysis of potential security options. USA. RAND Corporation. 
[20] Leidel, S. (2015). Travel Security Handbook. Zurich. Switzerland.

[21] Maithya, I. (2018). Countering involvement of Kenyan children in terrorism through realization of their socioeconomic rights. Journal of Law and Ethics, Vol 3, 2018, 107.

[22] Maluki, M. P. (2019). How Kenya Security Forces Made Sure They Responded Better This Time. https://africanarguments.org

[23] Mantell, R (2011). How 9/11 Terror Altered Job of Firefighters, Cops.

[24] Menya, A. A. (2016). Fire Disaster Mitigation and Preparedness in Nairobi. A Capacity Assessment of the City Fire Brigade. UON.

[25] Methu, S. (April, 6, 2015). Garisa University Attack. CNN

[26] Musau, N. (Sept, 21, 2014). Terrorist Exploited Well-Known Loopholes in Kenya. The Standard.

[27] National Fire Protection Association (NFPA, 2010). Massachusetts. USA.
[28] Ng'ang'a, K. (Apri, 25, 2019). CCTV Cameras Alone Cannot Prevent Crime. Daily Nation.

[29] Okere, S. (2012). An Evaluation of CCTV in Crime Management. A case study of Nairobi Central District.

[30] Ondego, O. (2016 Jun 17). Kenya Fights Insecurity with Technology. Nairobi. Kenya Alliance of Residents Association.

[31] Park et al (2012). International Journal of Law, Crime and Justice. Vol. 40. Issue 3, 179-191.

[32] Sethi, S. (2015). What is Security? Securitization and its Application in Turkey. University of New South Wales.

[33] Wafula, P. (2014 Aug 18). Kenya has experienced 100 attacks in 3 years. The Standard.

[34] Wong, C. (2002). Clifford R. Shaw and Henry D. McKay, The Social Disorganization Theory. CSISS Classics. UC Santa Barbara: Center for Spatially Integrated Social Science. Retrieved from https://escholarship.org/uc/item/47j411pr 